\title{
Refractory trace elements in Ca-Al-rich inclusions in the Allende meteorite
}

\author{
LaWrence Grossman* \\ Dept. of Geology and Geophysics, \\ Yale University, New Haven, Connecticut 06520, U.S.A. \\ (Received 31 July 1972; accepted in revised form 5 October 1972)
}

\begin{abstract}
The condensation temperatures are calculated for a number of refractory trace metals from a gas of solar composition at $10^{-3}$ and $10^{-4}$ atm. total pressure. Instrumental neutron activation analysis of $\mathrm{Ca}$-Al-rich inclusions in the Allende carbonaceous chondrite reveals enrichments of $22 \cdot 8 \pm 2 \cdot 2$ in the concentrations of $\mathrm{Ir}$, Sc and the rare earths relative to $\mathrm{Cl}$ chondrites. Such enrichments cannot be due to magmatic differentiation processes because of the marked differences in chemical behavior between Ir and Sc, exhibited by their distribu. tions in terrestrial igneous rocks and meteorites. All of these elements should have condensed from a cooling gas of solar composition above or within the range of condensation temperatures of the major mineral phases of the inclusions, which suggests that these inclusions are hightemperature condensates from the primitive solar nebula. Gas-dust fractionation of these materials may have been responsible for the depletion of refractory elements in the ordinary and enstatite chondrites relative to the carbonaceous chondrites.
\end{abstract}

\section{INTRODUCTION}

LORD (1965) PREDICTED that Ca-Al-'I'i-rich phases will be the first minerals to condense from a cooling gas of solar composition. Since then, white inclusions containing melilite, spinel, perovskite and diopside have been reported from a number of $\mathrm{C} 2$ and $\mathrm{C} 3$ chondrites (see, for example, CHRIstophe, 1968; KeIL et al., 1969; Fuchs, 1969; Kurat, 1970). Marvin et al. (1970) and Larimer and ANDERs (1970) suggested that these aggregates were high-temperature condensates from the solar nebula based on their high concentrations of $\mathrm{Ca}, \mathrm{Al}$ and Ti relative to $\mathrm{Mg}$ and $\mathrm{Si}$. ONUMA et al. (1972) have independently arrived at the same conclusion based on the oxygen isotopic composition of the white inclusions. Grossman (1972) and GrossMAN and Clark (1973) concluded that the mineral assemblages, textural relations and solid solution compositions of the minerals in the inclusions were formed in the solar nebula during high-temperature condensation processes.

The purpose of this study is, first, to calculate which trace elements are so refractory that they would have condensed over the range of condensation temperatures of the major phases of the inclusions and, second, to determine if any of these trace elements are enriched in the inclusions relative to the $\mathrm{Cl}$ chondrites.

\section{Theoretical Predictions}

ClaRk et al. (1972) have discussed briefly the high-temperature condensation of a number of refractory trace metals from a gas of solar composition. The following discussion is the result of more detailed calculations for which the formation of gaseous oxides of these metals and the stabilities of some of their crystalline oxides are also considered.

* Present address: Department of the Geophysical Sciences, University of Chicago, 5734 S. Ellis Avenue, Chicago, Illinois 60637. 
Table 1. Sources of free energy or vapor pressure data for refractory trace metals

\begin{tabular}{llcl}
\hline Gaseous species & Source & Crystalline phase & Source \\
\hline $\mathrm{Os}$ & 1 & $\mathrm{Sc}_{2} \mathrm{O}_{3}$ & 3 \\
$\mathrm{Sc}$ & 1 & $\mathrm{Ta}_{2} \mathrm{O}_{5}$ & $4,6,7$ \\
$\mathrm{ScO}$ & 2 & $\mathrm{ZrO}_{2}$ & 8 \\
$\mathrm{Re}$ & 1 & $\mathrm{Y}_{2} \mathrm{O}_{3}$ & 3 \\
$\mathrm{Ta}$ & 1 & $\mathrm{HfO}_{2}$ & 13,4 \\
$\mathrm{TaO}$ & 4,5 & $\mathrm{MoO}_{3}$ & 13 \\
$\mathrm{ZrO}, \mathrm{ZrO}_{2}$ & 8 & $\mathrm{VO}$ & 14 \\
$\mathrm{Zr}$ & 9 & $\mathrm{VO}_{2}$ & 15 \\
$W$ & 1 & $\mathrm{~V}_{2} \mathrm{O}_{3}$ & 13 \\
$\mathrm{WO}$ & 10,5 & $\mathrm{ThO}_{2}$ & 13 \\
$\mathrm{Y}$ & 1 & & \\
$\mathrm{YO}$ & 11 & & \\
$\mathrm{Hf}$ & 1 & & \\
$\mathrm{HfO}$ & 4,5 & & \\
$\mathrm{HfO}$ & 12 & & \\
$\mathrm{Mo}$ & 1 & & \\
$\mathrm{MoO}$ & 10,5 & & \\
$\mathrm{Ru}$ & 1 & & \\
$\mathrm{Ir}$ & 1 & & \\
$\mathrm{~V}$ & 1 & & \\
$\mathrm{VO}$ & 12 & & \\
$\mathrm{Th}$ & $\mathrm{ThO}, \mathrm{ThO}_{2}$ & 16 & \\
\hline
\end{tabular}

References:

1. Hultaren el al. (1964 and later). 2. Ames et al. (1967). 3. Holley et al. (1968). 4. Wagman el al. (1971). 5. Brewer and Rosenblatt (1969). 6. Kelley (1960). 7. Lewis et al. (1961). 8. JANAF Thermochemical Tables (1966). 9. JANAF Thermo. chemical Tables (1968). 10. Wagkan et al. (1969). 11. AckER. manN et al. (1964). 12. Chandraseikharaiat (1967). 13. Romie and Waldbaym (1968). 14. Glassner (1957). 15. Lord (1965). 16. ACkermanin and RaUh (1971).

Table 1 gives the sources of thermodynamic data for all gaseous and crystalline species considered. Free energies of gaseous $\mathrm{VO}$ and $\mathrm{HfO}_{2}$ were derived from vapor pressure data for crystalline $\mathrm{VO}$ and $\mathrm{HfO}_{2}$, respectively. The vapor pressures are order of magnitude estimates because of the uncertainties involved in the measurement of very low pressures at very high temperatures, the relatively complex vaporization behavior of these phases and the uncertainty in the exact molecular compositions of their coexisting vapors. These errors are reflected in the free energies of the gaseous species and consequently, in their condensation temperatures. Free energies of monatomic gaseous species were derived from vapor pressure curves usually having pressure uncertainties on the order of 25 per cent.

Condensation temperatures for the trace metals were calculated in a similar fashion to those of the major elements, as discussed by Grossman (1972). The partial pressure of each monatomic gaseous species as a function of temperature was calculated from the mass balance equation for each element and from the thermodynamic data for all the gaseous species considered for that element. Also required 
was the temperature variation of $P_{0}$, previously computed at $10^{-3} \mathrm{~atm}$. for each assemblage of major crystalline phases and found to be independent of pressure over a small pressure range (Grossman, 1972). The trace elements consume completely negligible quantities of oxygen, allowing the use of these data. Given the free energies of the crystalline phases containing each element and $P_{0}$, the partial pressure of that element necessary to condense each phase can be calculated as a function of temperature and compared to its actual partial pressure in the system. The first condensate of each element is the phase which reaches saturation at the highest temperature.

These calculations are summarized in Table 2. For each element, the gaseous species are listed in the third column in order of decreasing abundance at its condensation point. Equilibrium condensation temperatures at $10^{-3}$ and $10^{-4} \mathrm{~atm}$. total

Table 2. Molecular equilibria and condensation behavior of refractory trace metals

\begin{tabular}{|c|c|c|c|c|c|c|}
\hline Element & $\begin{array}{l}\text { Abundance* } \\
\left(\mathrm{Si}=10^{6}\right)\end{array}$ & $\begin{array}{l}\text { Gaseous species } \\
\text { considered }\end{array}$ & $\begin{array}{l}\text { Crystallino phases } \\
\text { considered }\end{array}$ & condensate & $\begin{array}{l}\text { ondensation }{ }^{\mathrm{Te}} \\
\left.=10^{-3} \mathrm{~atm}\right)\left(P_{\text {tot }}\right. \\
\left({ }^{\circ} \mathrm{K}\right)\end{array}$ & $\begin{array}{l}\text { emperature } \\
\left.=10^{-4} \mathrm{~atm}\right)\end{array}$ \\
\hline Os & $0 \cdot 71$ & $\mathrm{Os}$ & Os & Os & 1925 & 1840 \\
\hline W & $0 \cdot 16$ & Wo, w & $W$ & $w$ & 1885 & 1798 \\
\hline $\mathrm{Zr}$ & 30 & $\mathrm{ZrO}, \mathrm{ZrO}_{2}, \mathrm{Zr}$ & $\mathrm{Zr}, \mathrm{ZrO}_{2}$ & $\mathrm{ZrO}_{2}$ & 1840 & 1789 \\
\hline$R_{\theta}$ & 0.055 & $\mathrm{Re}$ & $\operatorname{Re}$ & $R_{e}$ & 1839 & 1759 \\
\hline $\mathrm{Hf}$ & $0 \cdot 16$ & $\mathrm{HfO} \approx \mathrm{HfO}_{2}, \mathrm{Hf}$ & $\mathrm{Hf}, \mathrm{HfO}_{2}$ & $\mathrm{HfO}_{2}$ & 1719 & 1652 \\
\hline $\mathbf{Y}$ & $4 \cdot 6$ & $\mathrm{YO}, \mathbf{Y}$ & $\mathrm{Y}, \mathrm{Y}_{2} \mathrm{O}_{3}$ & $\mathrm{Y}_{2} \mathrm{O}_{3}$ & 1719 & 1646 \\
\hline $\mathrm{Sc}$ & 33 & $\mathrm{ScO}, \mathrm{Sc}$ & $\mathrm{Sc}, \mathrm{So}_{2} \mathrm{O}_{3}$ & $\mathrm{Sc}_{2} \mathrm{O}_{3}$ & 1715 & 1644 \\
\hline Mo & $2 \cdot 52$ & Mo, MoO & $\mathrm{Mo}, \mathrm{MoO}_{3}$ & Mo & 1684 & 1603 \\
\hline Ir & 0.43 & Ir & Ir & Ir $\mathbf{r}$ & 1629 & 1555 \\
\hline $\mathbf{R u}$ & $1 \cdot 6$ & Ru & Ru & $\mathbf{R u}$ & 1614 & 1541 \\
\hline V & 900 & VO, V & $\mathrm{VO}_{2}, \mathrm{~V}, \mathrm{VO}, \mathrm{V}_{2} \mathrm{O}_{3}$ & $\mathrm{O}_{3} \mathrm{~V}_{2} \mathrm{O}_{3}$ & 1534 & 1458 \\
\hline $\mathrm{Ta}$ & 0.022 & $\mathrm{TaO}, \mathbf{T a}$ & $\mathrm{Ta}, \mathrm{Ta}_{2} \mathrm{O}_{5}$ & $\mathrm{Ta}_{2} \mathrm{O}_{5}$ & 1499 & 1452 \\
\hline Th & 0.034 & $\mathrm{ThO}_{2}, \mathrm{ThO}, \mathrm{Th}$ & $\mathrm{Th}, \mathrm{ThO}_{2}$ & $\mathrm{ThO}_{2}$ & 1496 & 1429 \\
\hline
\end{tabular}

* From Cameron (1968).

pressure are given in the final two columns. Only those elements are listed for which a phase condensed above the temperature for diopside condensation $\left(1450^{\circ} \mathrm{K}\right.$ at $10^{-3} \mathrm{~atm}$. Grossman, 1972). Among the elements which condense at lower temperatures than this are $\mathrm{U}, \mathrm{Nb}, \mathrm{Be}$, the rare earths, $\mathrm{Rh}, \mathrm{Pt}, \mathrm{Pd}, \mathrm{Au}$ and $\mathrm{Ag}$.

Gaseous and crystalline oxides of $O s, R e, R u$ and $I r$ are expected to play a winor role in the condensation behavior of these elements. Similarly, gaseous halides and hydrides of all the elements listed in Table 2 are assumed to be far less abundant than their corresponding oxides. Aside from these exceptions, the condensation temperatures listed in Table 2 may represent only lower limits because refractory carbides and nitrides of many of these elements may have higher condensation points than the phases considered here.

\section{Solid solution}

Solid solution effects dominate the condensation behavior of many trace elements. In the preceding calculations, the condensation point of each pure phase was calculated, i.e. each phase was assumed to condense at unit activity. It is clear, however, 
that the partial pressure necessary for condensation of any metal is lowered considerably if it is allowed to form a dilute solid solution in a suitable host phase. This always leads to the initiation of condensation at a higher temperature than in the case of a pure phase and could cause elements having condensation temperatures, as pure phases, below $1450^{\circ} \mathrm{K}$ to condense over the same range as those of Table 2 . Any element condensing at unil aulivily below $1758^{\circ} \mathrm{K}$, the condensation point of $\mathrm{Al}_{2} \mathrm{O}_{3}$, the first major condensate at $10^{-3} \mathrm{~atm}$. (Grossman, 1972), can begin to condense at $1758^{\circ} \mathrm{K}$ as a trace constituent in $\mathrm{Al}_{2} \mathrm{O}_{3}$ if it fits into the $\mathrm{Al}_{2} \mathrm{O}_{3}$ lattice. Since the atomic ratio of Al to many of these elements is $10^{5}$ to $10^{7}$, this process could lead to their total removal from the gas phase.

In particular, solid solution effects can be expected to allow the condensation of the rare earths over the same temperature range as that for the condensation of some of the elements listed in Table 2. The second major phase to condense, perovskite at $1647^{\circ} \mathrm{K}$, could provide lattice sites for the remuval of the rare earths, as well as other trace elements (Sc, Y, Zr). Terrestrial perovskites containing up to 11 per cent rare earths by weight have been reported by BoRodIN and BARINSKII (1960), demonstrating the affinity of the rare earths for the perovskite crystal structure. Condensation of the rare earth sesquioxides could thus begin at $1647^{\circ} \mathrm{K}$. Since the

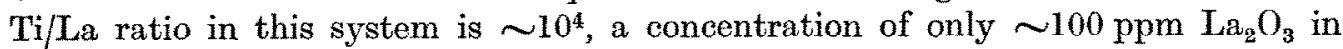
perovskite is required for total condensation of this element. Such a concentration could be achieved when pure $\mathrm{La}_{2} \mathrm{O}_{3}$ is still undersaturated by a factor of $10^{4}$, which would be at about $1500^{\circ} \mathrm{K}$ at $10^{-3} \mathrm{~atm}$. total pressure.

Although high-temperature data are lacking, the free energies of $\mathrm{SrTiO}_{3}$ and $\mathrm{BaTiO}_{3}$ at $298^{\circ} \mathrm{K}$ are very close to that of perovskite. Solid solution of these components in perovskite can be expected to cause the total condensation of $\mathrm{Sr}$ and $\mathrm{Ba}$ at temperatures in excess of $1450^{\circ} \mathrm{K}$ at $10^{-3} \mathrm{~atm}$, well above the condensation points of the pure components.

\section{Supersaturation}

From Table 2 it is evident that lowering the total pressure by a factor of ten usually causes the condensation temperatures to fall by about $50-100^{\circ}$. This is equivalent to saying that the system would be supersaturated by a factor of ten with respect to these phases at $50-100^{\circ}$ below their equilibrium condensation points. Thus, the final two columns of Table 2 can be used to estimate the degree of supersaturation of any of these elements at any temperature at $10^{-3}$ atm. Os, W, $\mathrm{ZrO}_{2}$ and Re would be supersaturated by factors of 10 to $10^{2}$ at the condensation temperature of corundum. These species could have crystallized by homogeneous nucleation from the supersaturated vapor at temperatures above $1758^{\circ} \mathrm{K}$ and could have served as heterogeneous nucleation sites for corundum at $1758^{\circ} \mathrm{K}$. Any lower temperature condensate of the major elements could have also nucleated on grains of these refractory trace elements, on grains of corundum or on grains of those trace elements which condense between $1758^{\circ} \mathrm{K}$ and its condensation point.

\section{Analytical Technigue}

\section{Sample preparation}

The trace element analyses described here are part of a cooperative study of the chemistry and mineralogy of the Ca-Al-rich inclusions in Allende (KrNG et al., 1973). At the University of 
Houston, slabs of the Allende meteorite were cut with a diamond saw, using Texaco Almag lubricant. Sixteen white, subspherical to irregular, polycrystalline inclusions were located by visual inspection of the slab surfaces and were removed by Dr. E. A. King with steel needles and accessories. Individual inclusions and a sample of the bulk meteorite were pulverized with an alumina mortar and pestle and shipped to Yale in polystyrene bottles with polyethylene caps. Subsequent X-ray and microscopic inspection of the inclusions by the Houston group revealed that they were all composed predominantly of gehlenite and spinel, with varying but usually lesser amounts of perovskite, diopside, anorthite, glass and perhaps another pyroxene.

At the Smithsonian Institution, bulk samples of Allende were crushed with a hardened steel pestle on a steel plute und ground with an agate mortar and pestle. One aliquot sent to Yale by Dr. E. Jarosewich and Dr. R. S. Clarke, Jr. was used in this study.

At Yale, the 16 powdered inclusions and the bulk sample of Allende supplied by the Smithsonian were dried for one hour at $110^{\circ} \mathrm{C}$ and re-ground in an agate mortar. From each sample, two 25 -mg aliquots were woighed into quartz irradiation vials. The vials were heat-sealed, washed in hot cone. $\mathrm{HNO}_{3}$ and weighed.

\section{Standards}

Duplicate 25-mg aliquots of the silicate rock standards GSP-1, BCR-1, G-1 and the "standard pot' (Perlman and Asaro, 1969; 'Turekian and Kharkar, 1970) were treated in exactly the same way as the samples and used as monitors for all elements except Ir and Au.

Twenty-mg aliquots of quartz powder were weighed into quartz irradiation vials. Standard solutions of $A u$ and Ir were prepared from specpure gold foil and $\left(\mathrm{NH}_{4}\right)_{2} \mathrm{IrCl}{ }_{6}$, respectively. Duplicate standards for each of these elements were made by pipetting $25 \mu \mathrm{l}$ aliquots of these solutions on to the quartz powder substrates inside the irradiation vials in an attempt to duplicate the geometry of the samples. They contained $0.625 \mu \mathrm{g} \mathrm{Au}$ and $10.23 \mu \mathrm{g} \mathrm{Ir}$, respectively. These standards were evaporated to dryness, heat-sealed, washed in hot conc. $\mathrm{HNO}_{3}$ and weighed.

Throughout all subsequent irradiation and counting, an empty irradiation tube and another containing only $20 \mathrm{mg}$ of quartz powder were run as blanks in parallel with all standards and samples.

\section{Irradiation and counting}

The vials were packed in an aluminum cylinder which was rotated about its axis, perpendicular to the neutron beam, at a constant speed throughout the irradiation. To further minimize any possible flux gradient perpendicular to the axis, the vials were arranged spirally such that one complete set of duplicate standards and samples was positioned closer to the cylinder axis than the other set. Since a flux gradient parallel to the axis was known to exist, all samples and standards were placed at the same height above the floor of the container.

Immediately on return to the laboratory, all vials were washed in hot cone. $\mathrm{HNO}_{3}$ and counted on $a 25 \mathrm{~cm}^{3} \mathrm{Ge}(\mathrm{Li})$ diode detector in reproducible geometry at a dead time of less than 20 per cent.

Irradiations were carried out in Union Carbide's reactor at Sterling Forest, New York. The sequence of irradiations and counting periods was identical to that used by TurkeraN and KHARKar (1970) and Kharkar and Turekian (1971).

All spectra for blanks, standards and samples were read out on paper tape. Suitable regions of the spectra for peak and background readings were located visually. Data processing was performed on an IBM 7094/7040 computer. The gamma-ray data reduction program corrected all peaks in all samples, standards and blanks for background and decay during counting, corrected these peak areas to the same point in time, subtracted blank corrections and, finally, compared the peak area of each element in every sample to the specific activity calculated for that element in every standard used. Errors due to counting statisties were propagated through the entire sequence of calculations.

A third $25-\mathrm{mg}$ aliquot of the first inclusion was selected for a fission track uranium determination using the method of BExTINe et al. (1970). A single aliquot of W-1 was used as a standard, at a concentration of $0.46 \mathrm{ppm} U$. 


\section{RESULTS}

\section{Standards}

The isotope counted and the concentration selected from the literature for each silicate standard used for each element are listed in Table 3. In the final column is given the relative

Table 3. Standards used for each element

\begin{tabular}{|c|c|c|c|c|c|c|}
\hline \multirow[b]{3}{*}{ Element } & \multirow[b]{3}{*}{ Isotope } & \multicolumn{4}{|c|}{ Concentration in silicate standards } & \multirow{3}{*}{$\begin{array}{c}\text { Range of specific } \\
\text { activities } \\
(\%)\end{array}$} \\
\hline & & BCR-1 & GSP-I & G-1 & $\mathrm{SP}$ & \\
\hline & & & & & & \\
\hline Mn & $\mathrm{Mn}^{56}$ & $\begin{array}{l}1320 \\
(2)\end{array}$ & $\begin{array}{l}317 \cdot 5 \\
(2)\end{array}$ & & & \pm 4 \\
\hline $\mathrm{Na}$ & $\mathrm{Na}^{24}$ & $\begin{array}{l}24000 \\
(2)\end{array}$ & $\begin{array}{l}20616 \\
(2)\end{array}$ & $\begin{array}{l}24200 \\
\text { (I) }\end{array}$ & $\begin{array}{l}2610 \\
(3)\end{array}$ & \pm 3 \\
\hline $\mathrm{La}$ & $L a^{140}$ & $\begin{array}{l}25 \cdot 20 \\
(2)\end{array}$ & & $\begin{array}{l}104 \\
\text { (1) }\end{array}$ & $\begin{array}{l}44 \cdot 90 \\
(3)\end{array}$ & \pm 3 \\
\hline $\mathrm{Sm}$ & $\mathrm{Sm}^{153}$ & & & & $\begin{array}{l}5 \cdot 78 \\
(3)\end{array}$ & \pm 1 \\
\hline $\mathrm{Au}$ & $A u^{198}$ & & & & & \pm 1 \\
\hline $\mathrm{Yb}$ & $Y b^{175}$ & & & & $\begin{array}{l}2 \cdot 80 \\
(3)\end{array}$ & \pm 2 \\
\hline $\operatorname{Ir}$ & $\operatorname{Ir}^{192}$ & & & & & \pm 1 \\
\hline $\mathrm{Fe}$ & $\mathrm{Fe}^{59}$ & $\begin{array}{l}92955 \\
(4)\end{array}$ & $\begin{array}{l}30200 \\
(4)\end{array}$ & & & \pm 1 \\
\hline Sc & $\mathrm{Sc}^{46}$ & $\begin{array}{l}33 \cdot 10 \\
(4)\end{array}$ & & & $\begin{array}{l}19 \cdot 85 \\
(4)\end{array}$ & \pm 1 \\
\hline Co & $\mathrm{Co}^{60}$ & $\begin{array}{l}35 \cdot 15 \\
(4)\end{array}$ & & & $\begin{array}{l}13 \cdot 10 \\
(4)\end{array}$ & \pm 1 \\
\hline Eu & $\mathrm{Eu}^{152}$ & $\begin{array}{l}2 \cdot 26 \\
(4)\end{array}$ & $\begin{array}{l}2 \cdot 79 \\
(4)\end{array}$ & & $\begin{array}{l}1 \cdot 43 \\
(4)\end{array}$ & \pm 3 \\
\hline
\end{tabular}

Sources of data: (1) selected from compilation of Flerscher (1969).

(2) selected from compilation of Flanagan (1969).

(3) Permiman and Asaro (1969).

(4) Katz and Grossman (1973).

range of specific activities measured in the standards for each element, to the nearest per cent. For Sm and Yb, only one silicate standard was used and the differences between the specific activities of duplicate standards are largely due to counting statistics. For $\mathrm{Mn}, \mathrm{La}$ and $\mathrm{Na}$, for which 2, 3 and 4 standards, respectively, were used, counting statistics usually fall far short of accounting for the differences in specific activities from one standard to the next. This reflects the uncertainty in the elemental concentration of the silicate standards. For Fe, Sc, Co and Eu, however, counting statistics again account for most of the difference between the specific activities of different standards. The data for these four elements were taken from Katz and GRossMAN (1973), who attempted to determine concentrations of these elements which are consistent with euch other in the silicate standards. Differences between duplicate Au and Ir standards represent counting uncertainty and the reproducibility of the preparation of pipetted standards. When comparing analytical data obtained in this study with those of other workers, the differing degrees of uncertainty in the concentrations of differont oloments in the silicate standards used here must be considered.

Where samples were compared to more than one standard for a single element, the different concentrations calculated for each sample were averaged.

\section{Samples}

All analyses are presented in Table 4. The A and B suffixes to the sample numbers denote separate $25-\mathrm{mg}$ aliquots of the same inclusion or semple of the bulk meteorite. For La, Sm, 
Table 4. Allende inclusions: results of instrumental neutron activation analysis. Values in ppm unless otherwise indicated; n.d. = not detected

\begin{tabular}{|c|c|c|c|c|c|c|c|c|c|c|c|}
\hline Sample & $\operatorname{Fe}(\%)$ & Mn & $\mathrm{Na}$ & $\mathrm{Sc}$ & La & $\mathrm{Sm}$ & Eu & $\mathrm{Yb}$ & Co & Ir & $\mathrm{Au}$ \\
\hline $1 \mathrm{~A}$ & 8.91 & 608 & 2520 & $79 \cdot 9$ & $3 \cdot 08$ & $1 \cdot 40$ & 0.58 & $1 \cdot 83$ & 250 & $7 \cdot 12$ & $0 \cdot 18$ \\
\hline $1 B$ & $8 \cdot 89$ & 659 & 2451 & $77 \cdot 0$ & $\pm 0 \cdot 11$ & \pm 0.02 & 0.90 & $\pm 0 \cdot 30$ & 249 & $7 \cdot 38$ & \pm 0.01 \\
\hline $2 \mathrm{~A}$ & $4 \cdot 40$ & 306 & 2027 & $109 \cdot 5$ & 3.94 & $2 \cdot 01$ & $1 \cdot 44$ & $2 \cdot 81$ & 139 & $10 \cdot 58$ & 0.40 \\
\hline $2 B$ & $4 \cdot 44$ & 335 & 2006 & $111 \cdot 8$ & $\pm 0 \cdot 11$ & \pm 0.03 & $1 \cdot 07$ & $\pm 0 \cdot 35$ & 139 & $10 \cdot 62$ & \pm 0.01 \\
\hline $3 \mathrm{~A}$ & $6 \cdot 34$ & 420 & 2073 & $116 \cdot 6$ & $3 \cdot 75$ & 1.89 & $1 \cdot 10$ & $1 \cdot 61$ & 186 & 8.48 & 0.58 \\
\hline $3 B$ & $6 \cdot 53$ & 451 & 2196 & $116 \cdot 3$ & \pm 0.12 & \pm 0.03 & 1.06 & $\pm 0 \cdot 36$ & 198 & $8 \cdot 87$ & \pm 0.01 \\
\hline $4 \mathrm{~A}$ & $9 \cdot 20$ & 690 & 2734 & $92 \cdot 0$ & $3 \cdot 84$ & $1 \cdot 86$ & 0.51 & 0.39 & 229 & $8 \cdot 44$ & 0.21 \\
\hline $4 B$ & $9 \cdot 37$ & 726 & 2814 & $99 \cdot 1$ & $\pm 0 \cdot 12$ & \pm 0.03 & 0.59 & $\pm 0 \cdot 34$ & 234 & $7 \cdot 63$ & \pm 0.01 \\
\hline $5 \mathrm{~A}$ & $3 \cdot 98$ & 276 & 896 & I 19.3 & $2 \cdot 94$ & $1 \cdot 66$ & 0.94 & $2 \cdot 69$ & 149 & $10 \cdot 69$ & $0 \cdot 17$ \\
\hline $5 B$ & $3 \cdot 88$ & 291 & 860 & $119 \cdot 8$ & $\pm 0 \cdot 10$ & \pm 0.03 & $1 \cdot 10$ & \pm 0.35 & 151 & $11 \cdot 85$ & \pm 0.01 \\
\hline $6 \mathrm{~A}$ & $5 \cdot 46$ & 404 & 8372 & $123 \cdot 7$ & $5 \cdot 03$ & $1 \cdot 68$ & $1 \cdot 27$ & $2 \cdot 47$ & 124 & $8 \cdot 39$ & $0 \cdot 16$ \\
\hline $6 \mathrm{~B}$ & $5 \cdot 46$ & 432 & 8289 & $124 \cdot 0$ & $\pm 0 \cdot 17$ & $\pm \mathbf{0 . 0 3}$ & 0.91 & \pm 0.37 & 123 & $9 \cdot 05$ & \pm 0.01 \\
\hline $7 \mathrm{~A}$ & $1 \cdot 45$ & 41 & 677 & $130 \cdot 1$ & $4 \cdot 60$ & $2 \cdot 40$ & 1.49 & $3 \cdot 21$ & 89 & $9 \cdot 22$ & $0 \cdot 14$ \\
\hline $7 \mathrm{~B}$ & $1 \cdot 37$ & 51 & 683 & $129 \cdot 7$ & $\pm 0 \cdot 11$ & \pm 0.03 & $1 \cdot 37$ & \pm 0.37 & 87 & $8 \cdot 36$ & \pm 0.01 \\
\hline $8 A$ & 6.55 & 740 & 25047 & $16 \cdot 8$ & 3.99 & $2 \cdot 18$ & 0.38 & n.d. & 105 & 0.18 & 0.48 \\
\hline $8 \mathrm{~B}$ & $6 \cdot 49$ & 797 & 23990 & $16 \cdot 6$ & \pm 0.25 & \pm 0.02 & 0.31 & & 103 & $0 \cdot 17$ & \pm 0.01 \\
\hline $9 A$ & $4 \cdot 63$ & 417 & 5408 & $39 \cdot 2$ & $3 \cdot 83$ & 1.79 & $1 \cdot 37$ & $2 \cdot 79$ & 119 & 6.55 & $0.2 €$ \\
\hline 913 & $4 \cdot 48$ & 420 & 5184 & $38 \cdot 4$ & $\pm 0 \cdot 13$ & \pm 0.03 & 1.45 & \pm 0.26 & 117 & $6 \cdot 34$ & \pm 0.01 \\
\hline $10 \mathrm{~A}$ & $9 \cdot 49$ & 722 & 8400 & $67 \cdot 4$ & $2 \cdot 90$ & $1 \cdot 53$ & 0.81 & $2 \cdot 20$ & 223 & $6 \cdot 38$ & $0 \cdot 12$ \\
\hline $10 \mathrm{~B}$ & $9 \cdot 40$ & 748 & 13214 & $67 \cdot 5$ & $\pm 0 \cdot 16$ & \pm 0.03 & 0.72 & $\pm 0 \cdot 32$ & 223 & $4 \cdot 79$ & \pm 0.01 \\
\hline $11 \mathrm{~A}$ & $8 \cdot 26$ & 644 & 5139 & $98 \cdot 5$ & 3.09 & $1 \cdot 64$ & 0.86 & 1.87 & 231 & $6 \cdot 48$ & 0.49 \\
\hline $11 \mathrm{~B}$ & $8 \cdot 33$ & 662 & 17714 & $98 \cdot 9$ & $\pm 0 \cdot 14$ & \pm 0.03 & 0.84 & $\pm 0 \cdot 36$ & 232 & $6 \cdot 70$ & \pm 0.01 \\
\hline $12 \mathrm{~A}$ & $7 \cdot 72$ & 638 & 4975 & $69 \cdot 8$ & $2 \cdot 97$ & $1 \cdot 54$ & $0 \cdot 84$ & $1 \cdot 35$ & 181 & $4 \cdot 89$ & $0 \cdot 20$ \\
\hline $12 \mathrm{~B}$ & $7 \cdot 69$ & 655 & 4801 & $70 \cdot 1$ & $\pm 0 \cdot 13$ & \pm 0.03 & 0.98 & $\pm 0 \cdot 31$ & 183 & $5 \cdot 13$ & \pm 0.01 \\
\hline $13 \mathrm{~A}$ & $2 \cdot 55$ & 189 & 1026 & $101 \cdot 8$ & $2 \cdot 92$ & $1 \cdot 50$ & $1 \cdot 05$ & $2 \cdot 28$ & 98 & $8 \cdot 15$ & $0 \cdot 25$ \\
\hline $13 B$ & $2 \cdot 57$ & 199 & 1012 & $101 \cdot 0$ & $\pm 0 \cdot 10$ & \pm 0.03 & $1 \cdot 18$ & $\pm 0 \cdot 35$ & 93 & $7 \cdot 29$ & \pm 0.01 \\
\hline $14 \mathrm{~A}$ & $3 \cdot 52$ & 292 & 2043 & $105 \cdot 1$ & $5 \cdot 19$ & $2 \cdot 70$ & $1 \cdot 00$ & $3 \cdot 42$ & 95 & $9 \cdot 44$ & $0 \cdot 34$ \\
\hline $14 \mathrm{~B}$ & $3 \cdot 63$ & 323 & 1880 & $105 \cdot 1$ & $\pm 0 \cdot 13$ & \pm 0.04 & 1.05 & \pm 0.37 & 94 & $10 \cdot 14$ & \pm 0.01 \\
\hline $15 \mathrm{~A}$ & $5 \cdot 52$ & 514 & 17019 & $102 \cdot 3$ & $3 \cdot 65$ & $2 \cdot 27$ & 1.04 & $2 \cdot 28$ & 99 & $8 \cdot 79$ & $0 \cdot 17$ \\
\hline $15 \mathrm{~B}$ & $5 \cdot 31$ & 506 & 16360 & 102.5 & \pm 0.21 & \pm 0.04 & 1.06 & $\pm 0 \cdot 38$ & 99 & 8.58 & \pm 0.01 \\
\hline $16 \mathrm{~A}$ & $8 \cdot 25$ & 563 & 2080 & $81 \cdot 4$ & & & $1 \cdot 23$ & & 215 & $8 \cdot 40$ & \\
\hline $16 \mathrm{~B}$ & $8 \cdot 28$ & 587 & 2027 & $81 \cdot 1$ & & & 1.01 & & 215 & $8 \cdot 93$ & \\
\hline SAA* & $23 \cdot 28$ & 1564 & 3668 & $11 \cdot 6$ & 0.47 & 0.22 & $0 \cdot 15$ & n.d. & 622 & 0.87 & $0 \cdot 16$ \\
\hline SAB & $22 \cdot 89$ & 1590 & 3608 & $11 \cdot 5$ & $\perp 0.09$ & \pm 0.03 & $0 \cdot 17$ & & 611 & 0.91 & \pm 0.01 \\
\hline KAA* & $22 \cdot 95$ & 1514 & 3708 & $11 \cdot 4$ & 0.50 & $0 \cdot 26$ & $0 \cdot 10$ & 0.47 & 616 & 0.91 & 0.22 \\
\hline \multirow[t]{3}{*}{$\mathrm{KAB}$} & $21 \cdot 84$ & 1580 & 3413 & $10 \cdot 6$ & \pm 0.09 & \pm 0.03 & 0.07 & $\pm 0 \cdot 29$ & 593 & 0.96 & $\pm 0 \cdot 01$ \\
\hline & \multicolumn{11}{|c|}{ Standard deviation of differences between duplicates } \\
\hline & $0 \cdot 14$ & 24 & 1010 & 0.9 & & & $0 \cdot \mathbf{I l}$ & & 3 & 0.44 & \\
\hline
\end{tabular}

* SA and KA are samples of the bulk meteorite.

$\mathrm{Yb}$ and $\mathrm{Au}$, only the $\mathrm{A}$ aliquot was counted, so the counting uncertainty in ppm is given as the best approximation to the precision of these determinations. For the elements for which duplicate determinations are available, the standard deviation of the differences between duplicates is given in the last line of Table 4. For any element, this is a mean measure of the reproducibility of its abundance in this suite of samples and includes all contributing factors such as uncertainty in the blank correction, counting uncertainty, weighing errors and sampling errors. The data indicate severe sample heterogeneity for Na. Poorer-than-average reproducibility is indicated for $\mathrm{Mn}$, Eu and Ir.

The U content of sample $\mathrm{lC}$ is $30 \pm 15 \mathrm{ppb}$.

The average Mn, La, Sm and Eu concentrations in the bulk sample of Allende supplied by the Smithsonian, SA, are within counting statistics of those in the sample supplied by King, KA. 
$\mathrm{Fe}, \mathrm{Na}$, Sc and Co are significantly higher and Ir and Au lower in SA than in KA, although differences between duplicate samples of KA are greater than the differences between the average values of $\mathrm{KA}$ and $\mathrm{SA}$ for $\mathrm{Fe}, \mathrm{Na}$ and $\mathrm{Co}$.

\section{Accuracy}

The concentrations of all 11 elements determined here in the bulk samples of Allende from both sources are compared to those reported for the Allende meteorite by other workers in Table 5. In the final column, the first line of data for each element applies to SA and the second

Table 5. Comparison of analyses of the Allende meteorite.

Values in ppm unless otherwise indicated. n.d. = not detected

\begin{tabular}{|c|c|c|c|c|c|c|c|c|c|}
\hline Element & $\begin{array}{l}\operatorname{KrNa} \\
(1969)\end{array}$ & $\begin{array}{l}\text { EMerY } \\
\text { et al. } \\
(1969)\end{array}$ & $\begin{array}{c}\text { Morgan } \\
\text { el al. } \\
(1969)\end{array}$ & $\begin{array}{l}\text { WAarria and } \\
\text { SchMrrT } \\
(1970)\end{array}$ & $\begin{array}{l}\text { ClaRtEe } \\
\text { et al. } \\
(1970)\end{array}$ & $\begin{array}{c}\text { WARnEN } \\
\text { (1971) }\end{array}$ & $\begin{array}{l}\text { BAEDEOKER } \\
(1972)\end{array}$ & $\begin{array}{c}\text { GILLUM and } \\
\text { EgMANM } \\
\text { (1971) }\end{array}$ & This work \\
\hline Mn & 1300 & 1700 & & $1450 \pm 40$ & 1400 & 1450 & & & $\begin{array}{l}1564,1590 \\
1514,1580\end{array}$ \\
\hline $\mathrm{Na}$ & 3000 & & $3300 \pm 100$ & $3370 \pm 100$ & 3300 & 3400 & & & $\begin{array}{l}3668,3608 \\
3708,3413\end{array}$ \\
\hline $\mathrm{Co}$ & 700 & 600 & $\begin{array}{l}684 \\
612\end{array}$ & $640 \pm 20$ & 600 & 640 & & & $\begin{array}{l}622,611 \\
616,593\end{array}$ \\
\hline $\mathrm{F} \varepsilon$ & $23.6 \%$ & $27.8 \%$ & $24 \cdot 4 \pm 0.4 \%$ & $21.9 \pm 0.4 \%$ & $23.85 \%$ & $23.9 \%$ & & & $\begin{array}{l}23.28 \%, 22.89 \% \\
22.05 \%, 21.84 \%\end{array}$ \\
\hline Se & & 10 & $12 \cdot 2 \pm 0 \cdot 2$ & $11 \cdot 0 \pm 0 \cdot 5$ & 11 & 11 & & & $\begin{array}{l}11 \cdot 6,11 \cdot 5 \\
11 \cdot 4,10 \cdot 6\end{array}$ \\
\hline Ir & & & $0.71 \pm 0.03$ & & & 0.71 & $0.78,0.80,0.81$ & & $\begin{array}{l}0 \cdot 87,0 \cdot 91 \\
0.91,0.96\end{array}$ \\
\hline$A_{\Perp}$ & & & $0.26 \pm 0.01$ & & & & & 0.21 & $\begin{array}{l}0 \cdot 16 \\
0 \cdot 22\end{array}$ \\
\hline $\mathrm{La}$ & & & & $0.44 \pm 0.02$ & 0.7 & & & & $\begin{array}{l}0 \cdot 47 \\
0.50\end{array}$ \\
\hline $\mathrm{Sm}$ & & & & $0.29 \pm 0.01$ & 0.5 & 0.31 & & & $\begin{array}{l}0.22 \\
0 \cdot 26\end{array}$ \\
\hline Eu & & & & $0.107 \pm 0.005$ & 0.1 & 0.113 & & & $\begin{array}{l}0 \cdot 15,0 \cdot 17 \\
0 \cdot 10,0 \cdot 07\end{array}$ \\
\hline $\mathrm{Y} b$ & & & & $0.32 \pm 0.02$ & 0.4 & & & & $\begin{array}{l}\text { n.d. } \\
0.47\end{array}$ \\
\hline
\end{tabular}

to $\mathrm{KA}$. The $\mathrm{Mn}, \mathrm{Co}, \mathrm{Fe}, \mathrm{Sc}, \mathrm{La}, \mathrm{Yb}$ and Eu determinations of this work are all within counting statistics of the ranges of values reported for these elements in the literature. Three of the $\mathrm{Na}$ values reported here and all the Ir determinations are slightly higher than the concentrations of these elements reported in the literature. One Sm and one Au value are significantly lower then those of other workers. The $\mathrm{Na}$ and $\mathrm{Sm}$ discrepancies may be related to uncertainties in the concentrations of these elements in the silicate standards, discussed above.

As far as the inclusions themselves are concerned, very little analy tical data have appeared in the literature. GAST et al. (1970) have reported rare earth abundances in a 'Ca-rich inclusion' from Allende. These data appear in Table 6 where they are compared with the ranges of concentration found in the suite of inclusions of the present study. It is evident that the inclusion. of $\mathrm{G}_{\mathrm{AS}} \mathrm{s}$ et al. (1970) is relatively rare earth-rich, having La and Eu abundances near the upper end of the ranges determined here and $\mathrm{Sm}$ and $\mathrm{Yb}$ values lying above the ranges reported here, but just within or slightly beyond the ranges of uncertainty due to counting statistics. The slightly lower Sm and $\mathrm{Yb}$ concentrations found in this study may be due to the adoption of low concentrations of these elements in the silicate standards.

Clarke et al. (1970) have described gehlenite-spinel-perovskite-bearing chondrules from Allende. In a systematic study of the abundances of 15 elements in 61 individual Allende chondrules, WARrEN (1971) has analyzed one containing 17.4 per cent $\mathrm{Al}, 12 \cdot 1$ per cent $\mathrm{Ca}$ and 1.25 per cent $\mathrm{Ti}$ ( $\mathrm{A}$ in Table 6 of this study) and another containing 13.6 per cent Al, 19.7 per cent $\mathrm{Ca}$ and 0.74 per cent $\mathrm{Ti}$ ( $\mathrm{B}$ in Table 6 ). In a similar study of the compositions of 36 Allende chondrules, MenninaA (1971) found one containing 8.71 per cent $A 1,2.5$ per cent $\mathrm{Ca}$ and 0.5 per cent $\mathrm{Ti}$ (C in Table 6). Although no mineralogical analyses aro availablo for any of these, 
Table 6. Comparison of analyses of Ca-rich inclusions in the Allende meteorite. Values in ppm unless otherwise indicated

\begin{tabular}{|c|c|c|c|c|c|}
\hline & \multirow{2}{*}{$\begin{array}{l}\text { GAST et al. } \\
\quad(1970)\end{array}$} & \multicolumn{2}{|c|}{ WARREN (197I) } & \multirow{2}{*}{$\underset{\text { C }}{\text { MEnNinga (1971) }}$} & \multirow[b]{2}{*}{ This work } \\
\hline & & A & $\mathrm{B}$ & & \\
\hline La & $4 \cdot 63 \pm 0 \cdot 19$ & & & & $2 \cdot 90-5 \cdot 19$ \\
\hline $\mathrm{Sm}$ & $2.82 \pm 0.11$ & $3 \cdot 0$ & $3 \cdot 4$ & & $1 \cdot 40-2 \cdot 70$ \\
\hline Eu & $1 \cdot 30 \pm 0.05$ & $1 \cdot 3$ & $1 \cdot 15$ & $0.31 \pm 0.04$ & $0 \cdot 31-1 \cdot 49$ \\
\hline $\mathrm{Yb}$ & $3.96 \pm 0.16$ & & & & $0 \cdot 39-3 \cdot 42$ \\
\hline $\mathrm{Na}$ & & $1.53 \%$ & $0.16 \%$ & $1.84 \pm 0.02 \%$ & $0.07 \%-2.50 \%$ \\
\hline $\mathrm{Sc}$ & & 117 & 133 & $64 \cdot 2 \pm 0.2$ & $16 \cdot 6-130 \cdot 1$ \\
\hline $\mathrm{Mn}$ & & 360 & 26 & $0.073 \pm 0.002 \%$ & $4 I-797$ \\
\hline $\mathrm{Fe}$ & & $5.8 \%$ & $0.37 \%$ & $9.65 \pm 0.08 \%$ & $1.37 \%-9.49 \%$ \\
\hline $\mathrm{Co}$ & & 76 & 8 & $282 \pm 2$ & $87-250$ \\
\hline Ir & & $5 \cdot 6$ & $5 \cdot 8$ & $3 \cdot 63 \pm 0 \cdot 03$ & $0 \cdot 17-11 \cdot 85$ \\
\hline $\mathrm{Au}$ & & & & $0.094 \pm 0.01$ & $0.12-0.58$ \\
\hline
\end{tabular}

they almost certainly contain gehlenite, spinel and perovskite. Eu, Na, Sc and Ir abundances in all of these chondrules lie within the concentration ranges for these elements determined in the present study. One $\mathrm{Fe}$, one Co and the $\mathrm{Sm}$ values lie slightly above the range reported here, but one $\mathrm{Mn}$, one $\mathrm{Fe}$, the $\mathrm{Au}$ and two Co determinations are lower than the lowest concentrations found here. It will be shown that a wide range of $\mathrm{Fe}$, Co and $\mathrm{Mn}$ concentrations may be expected, depending on the degree of contamination of the inclusions by matrix material. Again, the Sm data of this study are slightly lower than those of other workers. This may be related to uncertainty in the concentration of this element in SP.

\section{Discussion}

The data presented in Table 4 allow the elements considered in this study to be classified into three categories. Fe, $\mathrm{Mn}$ and Co fall into the first group of elements which are depleted in all of the inclusions relative to the bulk meteorite. The second class consists of the elements $\mathrm{Sc}, \mathrm{La}, \mathrm{Sm}, \mathrm{Eu}, \mathrm{Yb}$ and $\mathrm{Ir}$ which are enriched in all of the inclusions relative to the bulk meteorite (except for Ir in 8). In the final group are $\mathrm{Na}$ and $\mathrm{Au}$ which may have concentrations in the inclusions less than, equal to or greater than their respective abundances in the bulk meteorite. Furthermore, the three elements in group one display strong positive correlations with one another, as demonstrated by the Fe-Mn plot of Fig. 1. The elements of group two also show marked positive correlations with each other as shown for Sc-Ir in Fig. 2 but, in contrast, they each exhibit striking negative correlations with all of the elements of the first group. Finally, the elements of group three do not correlate positively or negatively with each other or with any of the elements of the other groups.

Table 7 is the correlation matrix for the 17 samples in which all 11 elements were determined. Table 8 is the correlation matrix of all 36 samples for which complete analytical data were available for only 7 elements. For 17 samples, a correlation coefficient greater than 0.56 is required for 99 per cent confidence that the pair of elements in question are correlated. For 36 samples, this critical value is 0.39 . Comparison of Tables 7 and 8 reveals that, in nearly every case, increasing the number of samples strengthens positive and negative correlations but results in lower correlation coefficients for pairs of elements which showed insignificant correlation in 17 samples. 


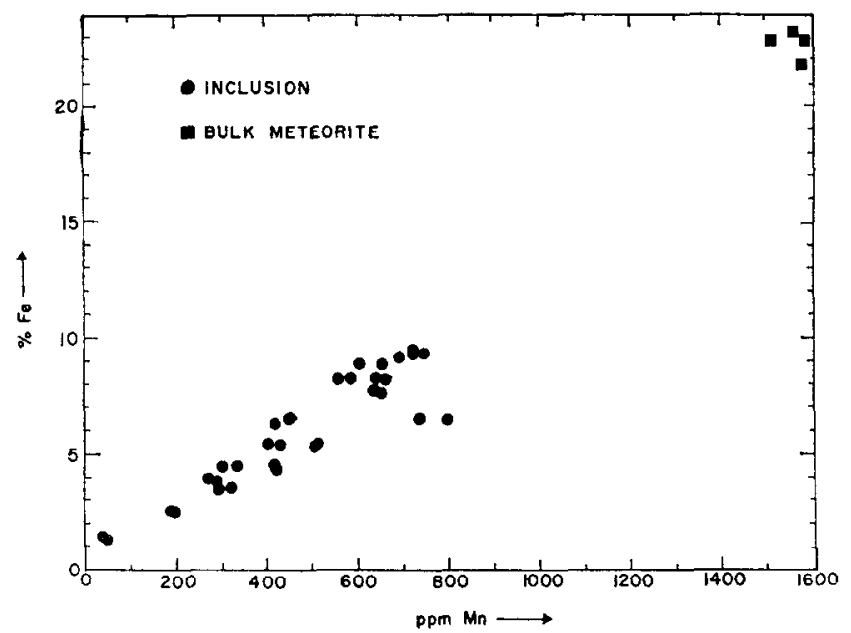

Fig. 1. The $\mathrm{Fe}-\mathrm{Mn}$ correlation in the Ca-rich inclusions from Allende. The pure inclusions contain very little $\mathrm{Fe}$ or $\mathrm{Mn}$. Their concentrations in these samples may be proportional to the degree of contamination of the pure inclusions by the meteorite matrix. Symbols are larger than the error bars due to counting statistics.

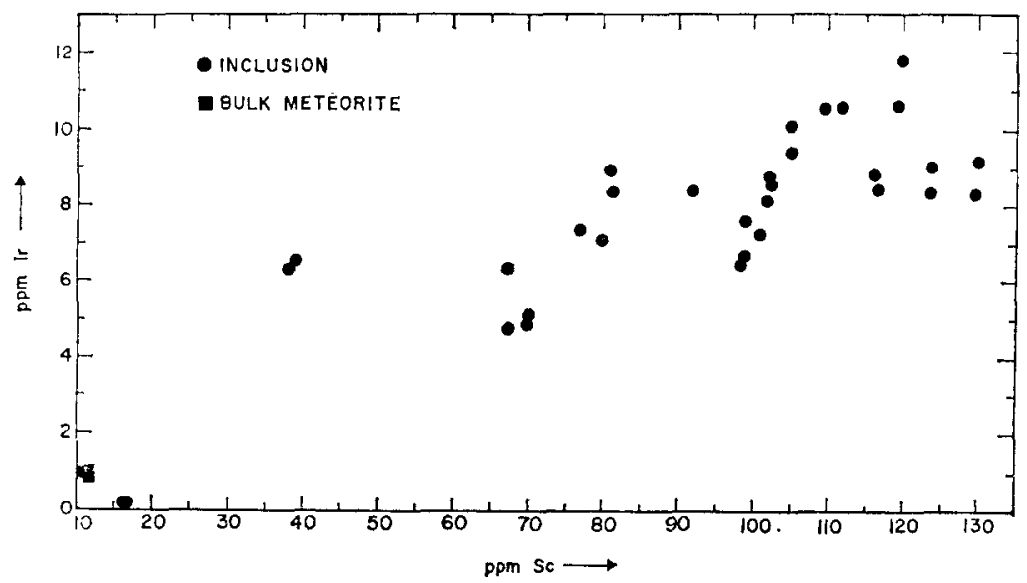

Fig. 2. The Ir-Sc correlation in the Ca-rich inclusions from Allende. The bulk meteorite contains very small amounts of Ir and Sc. In general, the samples least contaminated by matrix material are most enriched in Sc and Ir. Symbols are larger than the error bars due to counting statistics.

The simplest interpretation of the $\mathrm{Fe}-\mathrm{Mn}$-Co correlations is that their covariance plots represent two-component mixing lines where the high-iron end-member is the bulk meteorite and the low-iron component is the actual pure Ca-rich inclusion. Such mixing may have occurred by contamination of the inclusions with the meteorite matrix material at the time they were removed from the meteorite in the laboratory. Such reasoning implies that the pure inclusions contain $\leq 46 \mathrm{ppm} \mathrm{Mn,} \leq 1.4$ per cent Fe and $\leq 88 \mathrm{ppm} \mathrm{Co}$, the lowest concentrations found. KURAT (1970) has 
Table 7. Inter-element correlation coefficients for 17 samples*

\begin{tabular}{|c|c|c|c|c|c|c|c|c|c|c|}
\hline & $\mathrm{Na}$ & $\mathrm{Mn}$ & Se & La & $\mathrm{Sm}$ & Eu & $\mathrm{Yb}$ & $\mathrm{Co}$ & $\operatorname{Ir}$ & $\mathrm{Au}$ \\
\hline$F_{e}$ & -0.018 & 0.922 & -0.687 & -0.811 & -0.827 & $-0 \cdot 770$ & -0.681 & 0.924 & -0.699 & $-0 \cdot 164$ \\
\hline $\mathrm{Na}$ & & 0.148 & $-0 \cdot 348$ & $0 \cdot 126$ & $0 \cdot 197$ & -0.207 & -0.327 & $-0 \cdot 174$ & -0.417 & $0 \cdot 152$ \\
\hline $\mathrm{Mn}$ & & & -0.765 & -0.778 & -0.776 & -0.815 & -0.749 & $0 \cdot 874$ & -0.777 & -0.114 \\
\hline $\mathrm{Sc}$ & & & & 0.617 & 0.579 & 0.689 & $0 \cdot 663$ & -0.613 & 0.864 & 0.034 \\
\hline La & & & & & 0.867 & 0.674 & 0.570 & -0.833 & 0.598 & 0.203 \\
\hline Sm & & & & & & 0.622 & $0 \cdot 554$ & -0.851 & 0.584 & 0.264 \\
\hline Eu & & & & & & & 0.811 & $-0 \cdot 716$ & 0.731 & 0.069 \\
\hline $\mathrm{Yb}$ & & & & & & & & -0.607 & 0.753 & $-0 \cdot 104$ \\
\hline Co & & & & & & & & & -0.621 & -0.172 \\
\hline Ir & & & & & & & & & & -0.045 \\
\hline
\end{tabular}

* 99 per cent confidence level is 0.56 .

reported the results of microprobe analyses of gehlenite-bearing inclusions from Lancé. His $\mathrm{Fe}(0 \cdot 16$ per cent) and $\mathrm{Mn}(<400 \mathrm{ppm})$ data confirm the relatively low abundances of these elements in the pure inclusions inferred from the present study. Clarke et al. (1970) described a similar inclusion in Allende which contains 1.8 per cent $\mathrm{Fe}$, undetectable $\mathrm{Mn}$ and $<100 \mathrm{ppm}$ Co as well as a gehlenite-bearing chondrule containing only 0.29 per cent $\mathrm{Fe}, 160 \mathrm{ppm} \mathrm{Mn}$ and $<100 \mathrm{ppm}$ Co. Since these data are based on physically separated samples, they may suffer from the same contamination problem reported here. The Fe analyses of Table 4 thus indicate that most of the inclusion samples are contaminated with between 10 and 25 per cent matrix material, not an unreasonable amount considering that their total masses are sometimes less than $100 \mathrm{mg}$ and their average diameter is only $6-7 \mathrm{~mm}$. Although no smooth trend of increasing contamination with decreasing sample size is present, it is worthy of note that the highest Fe content $(9.45$ per cent) is in the smallest inclusion (72 $\mathrm{mg}$ ) and the lowest Fe (1.41 per cent) is found in an inclusion weighing $259 \mathrm{mg}$.

Similarly, the marked negative correlations of group two elements with those of group one can also be interpreted as mixing curves, with the concentrations of Sc, Ir and the rare earths decreasing with increasing dilution of the inclusions by matrix material. The scatter of the data observed in the correlation plots for group two elements (Fig. 2, for example) may indicate that the pure inclusions themselves, though all enriched in these elements, contain variable concentrations of them, perhaps correlating with the abundance of one or two of the minerals of the inclusions.

Table 8. Inter-element correlation coefficients for 36 samples*

\begin{tabular}{lcccrrr}
\hline & $\mathrm{Na}$ & $\mathrm{Mn}$ & $\mathrm{Sc}$ & $\mathrm{Eu}$ & \multicolumn{1}{c}{$\mathrm{Co}$} & \multicolumn{1}{c}{ Ir } \\
\hline $\mathrm{Fe}$ & -0.011 & 0.951 & -0.704 & -0.796 & 0.954 & -0.699 \\
$\mathrm{Na}$ & & 0.158 & -0.312 & -0.267 & -0.160 & -0.425 \\
$\mathrm{Mn}$ & & & -0.786 & -0.850 & 0.900 & -0.785 \\
$\mathrm{Se}$ & & & & 0.682 & -0.627 & 0.880 \\
$\mathrm{Eu}$ & & & & & -0.734 & 0.751 \\
$\mathrm{Co}$ & & & & & & -0.616 \\
\hline
\end{tabular}

* 99 per cent confidence level is 0.39 . 
In the same way, the scatter observed in the plots for the first group of elements suggests that the meteorite matrix is also inhomogeneous in composition.

Figure 3 is a plot of the $\mathrm{Fe}$ concentrations in the inclusions versus the $\mathrm{Na}$ contents. Kurat's (1970) microprobe data show $<1500 \mathrm{ppm} \mathrm{Na}$ and $<400 \mathrm{ppm} \mathrm{Na}$

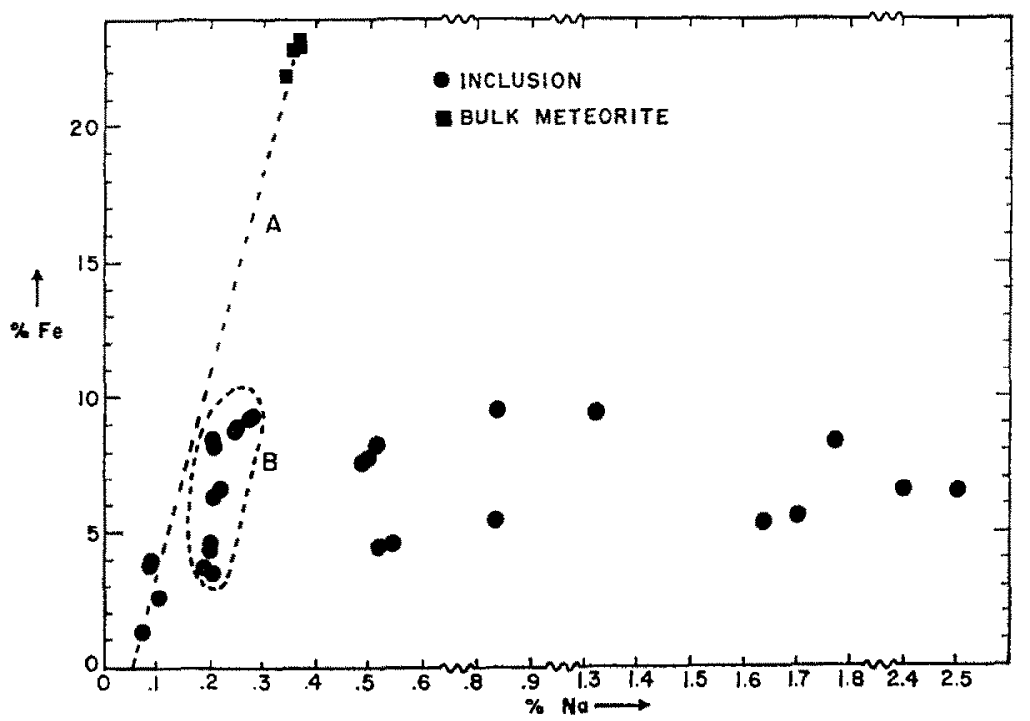

Fig. 3. $\mathrm{Na}$ and $\mathrm{Fe}$ abundances in the Ca-rich inelusions from Allende. There is some suggestion of mixing between a $\mathrm{Na}-\mathrm{Fe}$-rich bulk meteorite component and a $\mathrm{Na}-\mathrm{Fe}$-poor inclusion component, but many samples show evidence of the addition of a third Na-rich component. Symbols are larger than the error bars due to counting statistics.

for two Lancé inclusions, significantly lower $\mathrm{Na}$ abundances than most of the analyses of Table 4. If the inclusions of this study were contaminated with matrix material, the points in Fig. 3 should plot along a line such as that labelled 'A', connecting the bulk meteorite $(\sim 3600 \mathrm{ppm} \mathrm{Na}$ ) composition with one representing the average pure inclusion $(<0.5$ per cent $\mathrm{Fe},<1000 \mathrm{ppm} \mathrm{Na})$. There is only a slight suggestion that such a linear array exists, with the cluster of points ' $\mathrm{B}$ ' appearing to have a relatively small excess of $\mathrm{Na}$ over that cxpectcd from their $\mathrm{Fe}$ content. The remaining one-third of the $\mathrm{Na}$ analyses are greater than $4500 \mathrm{ppm}$ and bear no relationship to the $\mathrm{Fe}$ contents. Among these are inclusions 10 and 11, for which duplicate $\mathrm{Na}$ analyses differ by factors of $>2$ and $>3$, respectively, indicating the possible presence of a poorly-sampled, trace, Na-rich mineral suggestive of the rare occurrence of nepheline and other feldspathoids in similar inclusions (CHRISTOPHE, 1969; Fuchs, 1969; Marvin et al., 1970; Clarke et al., 1970). Thus, in order to account for the Na content of these samples, a third component must be present, in addition to the primitive inclusion component and the meteorite matrix component.

The Au concentrations bear no relationship to the abundances of any other element determined (see Table 7). They vary from $0.12 \mathrm{ppm}$ to $0.58 \mathrm{ppm}$, whereas the average $\mathrm{Au}$ content of the bulk meteorite is $0.19 \mathrm{ppm}$ (see Table 4). Since Au 
does not correlate with $\mathrm{Na}$, it could only have entered the inclusions with the Na-rich component if this third component had a variable $\mathrm{Au} / \mathrm{Na}$ ratio. Since it does not correlate with any of the elements of group one, it could only be associated with the matrix contamination if the matrix is much more heterogeneous with respect to $\mathrm{Au}$ than to $\mathrm{Fe}$, Co and $\mathrm{Mn}$. That such heterogeneities do indeed exist in Allende is supported by the data of WARREN (1971) which show that the Au/Fe ratio can vary from $1.04 \times 10^{-6}$ to $2.54 \times 10^{-5}$ from chondrule to chondrule in Allende. MenNonga (1971) found this ratio to vary from $1.13 \times 10^{-7}$ to $4.3 \times 10^{-6}$ in his study of individual Allende chondrules. It appears then that the rather wide range of $\mathrm{Au}$ values found here could have been generated by varying degrees of contamination by a matrix exceedingly heterogeneous with respect to $\Lambda u$.

If we correct the Ir, Sc, La, Sm, Eu and $\mathrm{Y} b$ concentrations of all inclusions for matrix contamination, assuming that the pure inclusions contain no $\mathrm{Fe}$, $\mathrm{Co}$ or $\mathrm{Mn}$, we can compare them to the abundances of these elements in the Cl's Ivuna and Orgueil in order to better understand the condensation process. The data so corrected and compared appear in Table 9 where it can be seen that the pure inclusions are enriched in these elements by factors of 18.3 to $25 \cdot 7$ relative to Cl's. It will be shown that such high concentrations of these elements are unlikely to have resulted from magmatic differentiation but are quitc consistent with an origin for these inclusions by condensation processes.

Table 9. Average elemental concentrations in Ca-rich inclusions, corrected for matrix contamination, and enrichment factors relative to Cl's

\begin{tabular}{cccc}
\hline & $\begin{array}{c}\text { Average concentration } \\
\text { in pure Ca-rich inclusions } \\
(\mathrm{ppm})\end{array}$ & $\begin{array}{c}\text { Average concentration } \\
\text { in Orgueil and Ivuna } \\
(\mathrm{ppm})\end{array}$ & $\begin{array}{c}\text { Enrichment } \\
\text { factors* }\end{array}$ \\
\hline $\mathrm{Ir}$ & $10 \cdot 9$ & $0 \cdot 15^{1}$ & $\mathbf{2 4 \cdot 1} \pm 1 \cdot 6$ \\
$\mathrm{Sc}$ & $128 \cdot 1$ & $5 \cdot 6^{2}$ & $22 \cdot 9 \pm 5 \cdot 1$ \\
$\mathrm{La}$ & $4 \cdot 9$ & $0 \cdot 19^{2}$ & $25 \cdot 7 \pm 4 \cdot 7$ \\
$\mathrm{Sm}$ & $2 \cdot 4$ & $0 \cdot 133^{2}$ & $18 \cdot 3 \pm 3 \cdot 0$ \\
$\mathrm{Eu}$ & $1 \cdot 4$ & $0 \cdot 053^{2}$ & $25 \cdot 6 \pm 4 \cdot 9$ \\
$\mathrm{Yb}$ & $2 \cdot 8$ & $0 \cdot 137^{2}$ & $20 \cdot 4 \pm 6 \cdot 7$ \\
\hline
\end{tabular}

Sources of $\mathrm{Cl}$ abundance data:

1. Average of Ehmann et al. (1970) and Crocket et al. (1967).

2. Schmiтt et al. (1964).

* Enrichment factor = average concentration in Ca-rich inclusion/average concentration in Orgueil and Ivuna.

\section{Ir and Sc in terrestrial igneous rocks}

Although a search of the literature reveals little detailed understanding of the behavior of Ir during terrestrial magmatic differentiation, the following general observations have been made. CROCKet (1969) has confirmed that the platinum metals, as a group, are enriohed in terrestrial basic and ultrabasic rocks relative to granites. In particular, GREENLAND (1971) has found that the Ir concentrations in a differentiated tholeiitic intrusion decrease from 0.25 $\mathrm{ppb}$ in the mafic zone to $0.006 \mathrm{ppb}$ in the salic zone. In the same study, a close correlation was evident between $\mathrm{Ir}$ and $\mathrm{Cr}$ concentrations, perhaps related to crystallochemical simularities between $\mathrm{Ir}^{4+}$ and $\mathrm{Cr}^{3+}$. This correlation was obscured only in the zone of sulphide precipitation, where Ir was enriched relative to Cr. RAZIN et al. (1965), in a study of the distribution of the platinum metals in the Inaglinsk Massif, discovered 200-900 ppb Ir in chrome-spinel-bearing 
dunites and only $0 \cdot 4-40 \mathrm{ppb}$ in the associated pyroxene-bearing rocks. They also found that chrome-spinel contained an average of 30 times more platinum metals than coexisting olivine. During the normal course of terrestrial magmatic differentiation, it appears that the depletion of $\mathrm{Ir}$ in acidic rocks relative to basic ones is related to its strong fractionation into hightemperature chromite crystals and sulphide liquids.

In terrestrial igneous rocks, the distribution of Se is controlled primarily by its affinity for the crystal structures of pyruxene and amphibole. The summary by Frovaes (1970) shows that Sc rarely exceeds $10 \mathrm{ppm}$ in dunites and peridotites and $50 \mathrm{ppm}$ in basalts and gabbros. On the other hand, pyroxenites and hornblendites may have Sc contents up to $200 \mathrm{ppm}$ while the Sc concentration in andesites and granites is usually less than $20 \mathrm{ppm}$.

It seems that the only product of normal terrestrial magmatic processes which could potentially concentrate both Ir and Se would be a chromite- or sulphide-bearing pyroxenite. Although it can be argued that the gehlenite-spinel-perovskite-bearing inclusions in the C3's commonly contain a mineral having the spinel structure and often contain pyroxene, the omnipresent gehlenite and perovskite, if magmatic in origin, would indicate a substantially different and more complex pre-crystallization history than a chromite-pyroxenite. Sulphides have only rarely been observed inside the inclusions. Microprobe analyses of spinels in the Lancé inclusions (KuRAT, 1970) show that their compositions are very close to the $\mathrm{Mg}-\mathrm{Al}$ end-member, containing 0.1 to 8 per cent $\mathrm{FeO}$ and a maximum of only 0.3 per cent $\mathrm{Cr}_{2} \mathrm{O}_{3}$, much lower than Ir-enriched terrestrial spinels. Also, the Ca-Al-rich inclusions never contain olivine, not even as an accessory mineral, unlike Ir-enriched, spinel-bearing terrestrial ultrabasic rocks.

\section{Ir and Sc in meteorites}

The Ir content of carbonaceous, enstatite and ordinary chondrites usually lies between 0.2 and $0.9 \mathrm{ppm}$ while that of achondrites is as much as 100 times lower (EhMANN and REBAGAY, 1970; Crocket et al., 1967; Müller et al., 1971). The Ir concentrations in ordinary chondrites are related to their metallic iron contents, the $H$ group containing $0.7-0.8 \mathrm{ppm}$ and the $L$ group 0.4-0.5 ppm (MüLler et al., 1971). The metal phase of the Eagle Station pallasite was found to contain $2.81 \mathrm{ppm}$ Ir while the silicate phase contains only $0.13 \mathrm{ppb}$ (BAEDECKER, 1967), demonstrating the siderophile behavior of Ir. Meteoritic metal usually contains 10-40 times more Ir than coexisting sulphides (Ermann et al., 1970). Meteoritic silicates containing more than $1 \mathrm{ppm}$ Ir are extremely rare, but iron meteorites often have Ir concentrations between 1 and $60 \mathrm{ppm}$ (CoBB, 1967; Wasson, 1969).

Because of the siderophile behavior of Ir, processing of metal-bearing meteoritic matter seems insufficient to concentrate Ir to the levels observed in the metal-free Ca-rich inclusions. That their Ir concentrations are not associated with metal or sulphide grains is confirmed by the strong negative correlation of Ir with both Fe and Co.

Sc concentrations in meteorites have been summarized by Frondec (1970). The abundance of Sc seldom exceeds $10 \mathrm{ppm}$ in chondrites, but usually falls between 25 and $50 \mathrm{ppm}$ in achondrites. Sc concentrations in excess of $100 \mathrm{ppm}$ are very rare in meteoritic materials and could only be produced from them via severe fractionation processes.

The mineralogy and trace element content of the Ca-rich inclusions thus appear to rule out their origin by normal magmatic differentiation processes acting on observed meteoritic starting materials. 


\section{Condensation of the refractory elements}

On the other hand, the condensation of a cooling gas of solar composition is expected to result in the enrichment of the early condensate phase assemblage in the elements of Table 2. At a total pressure of $10^{-3}$ to $10^{-4} \mathrm{~atm}$., Sc, Ir and the rare earths condense over the same temperature range as corundum, perovskite, melilite and spinel. CROcket et al. (1967) were the first to point out the high condensation temperature of Ir. Larimer and Anders (1970) and EhmanN and Grblum (1972) suggested that the least volatile siderophile elements may have been fractionated with the refractory lithophile elements.

Many workers have noted relatively high concentrations of some of the other refractory elements in Ca-rich inclusions similar to those studied here. KURAT (1970) has described perovskite containing $2 \cdot 2$ per cent $\mathrm{ZrO}_{2}$ and $1 \cdot 1$ per cent $\mathrm{Y}_{2} \mathrm{O}_{3}$ from a Lancé inclusion whose overall $\mathrm{Zr}$ and $\mathrm{Y}$ concentrations were calculated to be $\sim 1500$ $\mathrm{ppm}$ and $\sim 800 \mathrm{ppm}$, respectively. These represent substantial enrichments relative to their concentrations in C3's, 9-12 ppm Zr and 2-3 ppm Y (Clarke et al., 1970). Ehmann and Rebagay (1970) have reported average $\mathrm{Zr}$ and Hf concentrations in 'white inclusions' from Allende of $24 \mathrm{ppm}$ and $0.36 \mathrm{ppm}$, as compared to abundances in the black matrix of $1.6 \mathrm{ppm}$ and $0.14 \mathrm{ppm}$, respectively.

If the major condensates began to nucleate only on pre-existing refractory grains of $\mathrm{Os}, \mathrm{W}, \mathrm{ZrO}_{2}$ and $\mathrm{Re}$, a very large fraction of each of these trace metals may have been physically trapped inside corundum, perovskite and melilite crystals. Similarly, once condensation of these major phases had begun, their crystals could have provided suitable substrates for the condensation of the remaining refractories, $\mathrm{HfO}_{2}$, $\mathrm{Y}_{2} \mathrm{O}_{3}, \mathrm{Sc}_{2} \mathrm{O}_{3}, \mathrm{Mo}, \mathrm{Ir}, \mathrm{Ru}, \mathrm{V}_{2} \mathrm{O}_{3}, \mathrm{Ta}_{2} \mathrm{O}_{5}$, ThO $\mathrm{O}_{2}$ and the rare earths and any supersaturated, uncondensed, higher-temperature refractories, either by providing heterogeneous nucleation sites for them or by providing crystal structures suitable for the formation of solid solutions with some of them. The crystallization of the major phases probably was a very efficient mechanism for the scavenging of the trace metals from the vapor.

That these high-temperature condensates have also been involved in the chondrule-forming process is indicated by the high refractory element concentrations in some Allende chondrules reported by WarReN (1971) and Menninga (1971), as seen in Table 6. In addition, two other $\mathrm{Ca}-\mathrm{Al}-\mathrm{Ir}$-rich Allende chondrules reported by WARREN (1971) contain 980 and $710 \mathrm{ppm} V$ while normal chondrules contain only 100-200 ppm V. OsBons (1971) reported a chondrule from the C4 Karoonda which contains 22.5 per cent $\mathrm{Al}, 87 \mathrm{ppm} \mathrm{Sc}$ and $24 \mathrm{ppm} \mathrm{Ir}$ and OsBonN $t$ al. (1973) have discovered Ir-Al and Ir-Sc correlations in chondrules from ordinary chondrites.

\section{The Na-rich component}

The high $\mathrm{Na}$ concentrations sometimes observed in these $\mathrm{Ca}-\mathrm{Al}$-rich inclusions are probably related to the presence of small quantities of feldspathoids such as nepheline $\left(\mathrm{NaAlSiO}_{4}\right)$ and sodalite $\left(3 \mathrm{NaAlSiO}_{4} \cdot \mathrm{NaCl}\right)$ which have sometimes been reported as accessory phases in similar inclusions in Allende and other $\mathrm{C} 3$ chondrites (see references above). These minerals are probably also the hosts for high concentrations of $\mathrm{K}$ (GAST $t$ al., 1970), I and $\mathrm{Xe}^{129}$ (PodoseK and Lewis, 1972). Equilibrium calculations show that both of these minerals could only condense from 
a gas of solar composition at temperatures below $1000^{\circ} \mathrm{K}$ and they probably would not appear even then due to the removal of $\mathrm{Na}$ from the vapor by feldspars above $1100^{\circ} \mathrm{K}$. Such phases are thus completely out of condensation equilibrium with the major minerals of the inclusions, which are stable condensates in equilibrium with the gas between $1750^{\circ}$ and $1450^{\circ} \mathrm{K}$ at $10^{-3} \mathrm{~atm}$.

ArRhenius and Aly'vén (1971) and Arrhenius (1972) have proposed that this apparently anomalous coexistence of $\mathrm{Ca}$-Al-rich refractory compounds with alkalihalogen-rich volatile minerals can be explained by condensation of low-temperature grains from a very low-pressure, high-temperature plasma. In this model, ionization effects control the condensation sequence, with $\mathrm{Ca}, \mathrm{Al}$ and $\mathrm{Ti}$ only becoming neutral at gas temperatures between $5000^{\circ}$ and $6000^{\circ} \mathrm{K}$, when $\mathrm{Na}$ also becomes available for condensation. They claim that grains forming at these plasma temperatures have temperatures below the condensation points of both feldspathoids and $\mathrm{Ca}-\mathrm{Al}$ silicates and, consequently, they condense together. But Ir becomes neutral at $10,000^{\circ} \mathrm{K}$, when grain temperatures are below its condensation point. Similarly, $\mathrm{Mg}$ and $\mathrm{Si}$ are neutral at $8000^{\circ} \mathrm{K}$, when grain temperatures are below the condensation temperatures of forsterite and enstatite, even at the extremely low pressures envisioned by these workers. It is difficult to understand why these inclusions contain Ir, having high neutralization and condensation temperatures, and feldspathoids, having low neutralization and condensation temperatures, while the common meteoritic magnesium silicates, with intermediate temperatures, are absent (FucHs, 1969). The ionization-controlled condensation model fails to account for these observations.

The author has previously suggested (Grossman, 1972) that the feldspathoids in the inclusions have little to do with condensation processes, but are the result of later, secondary reactions between high- and low-temperature condensates in the meteorite parent bodies. The necessity of a third, extraneous, Na-rich component to account for the $\mathrm{Na}$ abundances in the samples studied here is in agreement with this hypothesis. The I-Xe data of Podosek and Lewis (1972) show that the I and therefore probably the $\mathrm{Cl}$, were emplaced in the inclusions at an early date. The data also suggest that the feldspathoids may have formed over a $4 \mathrm{~m}$.y. time span, which is probably 10 to 100 times longer than the condensation time of the solar system (CLARK et al., 1972).

\section{Enrichment factors}

At complete equilibrium, the condensate phase assemblage at $1450^{\circ} \mathrm{K}$ and $10^{-3}$ atm. total pressure contains 100 per cent of the total $\mathrm{TiO}_{2}, \mathrm{Al}_{2} \mathrm{O}_{3}$ and $\mathrm{CaO}$ as well as 10 per cent of the $\mathrm{MgO}$ and 14 per cent of the $\mathrm{SiO}_{2}$ in the system. This temperature is thought to be close to that at which reaction ceases between vapor and the hightemperature condensate phase assemblage of the Ca-Al-rich inclusions (GrossmaN, 1972). If it is assumed that the average analyses of the Orgueil and Ivuna Type I carbonaceous chondrites (WIIK, 1956) are representative of the mean composition of the condensable matter of the solar system, one can calculate that the $1450^{\circ} \mathrm{K}$ equilibrium condensate assemblage would have consumed 8.03 weight per cent of the total condensable matter. If the refractory trace metals were each scavenged from the vapor by these high-temperature condensates with 100 per cent efficiency, 
they should show concentration enrichments of $100 / 8 \cdot 03=12 \cdot 48$ relative to their mean concentrations in Orgueil and Ivuna. Such enrichments are approximately a factor of two lower than those actually observed (see Table 9). KuRAT (1970), however, reported that the diopside forms narrow rims surrounding the inclusions in Lancé, indicating that most of the melilite did not take part in the reaction to form diopside and that equilibrium was not attained at $1450^{\circ} \mathrm{K}$ (GRossman, 1972). If the formation of diopside at this temperature is neglected, the condensate phase assemblage is calculated to have consumed $5.59 \mathrm{wt} . \%$ of the condensable matter, leading to an enrichment factor of $\mathbf{1 7 . 9}$, which is much closer to the observed enrichment factors of 18.3 to 25.7 seen in Table 9 . Consideration of the fact that much highgehlenite melilite also remains preserved in the cores of the inclusions suggests that they contain only about $4.46 \mathrm{wt} \%$ of the condensable matter. This leads to an enrichment factor of $\mathbf{2 2 . 4}$ in the range of those observed. Alternatively, if the trace refractories were scavenged from the vapor with less than 100 per cent efficiency, the observed enrichments can be explained if the solar system is richer in the refractory elements than is indicated by their abundances in $\mathrm{Cl}$ chondrites. The high-temperature inclusions, having concentrated the trace refractories, may have then been fractionated from the material which was ultimately incorporated into the $\mathrm{Cl}$ chondrites. Preservation of the smoothness of the curve of elcmental abundance versus mass number is still possible even if the true solar system abundances of the trace refractories are a factor of 1.5 higher than those given by CAMERON (1968), as suggested by ANDERs (1971).

\section{Rare earths}

The rare earth abundances of four typical inclusions and the bulk meteorite have been normalized, element by element, to their abundances in a composite of nine chondrites (HASKIN et al., 1968) and plotted in Fig. 4 as a function of atomic number. Despite the large uncertainties in the concentrations of $\mathrm{Eu}$ and $\mathrm{Yb}$, it is clear that the bulk meteorite is enriched in the rare earths by about 40-50 per cent relative to the chondrite composite, probably due to the high content of Ca-rich inclusions, which are highly enriched in the rare earths. The most striking feature of the rare earth pattern of these inclusions is the significant Eu excess, like that in $2 \mathrm{~A}$ and $6 \mathrm{~A}$, found in about 75 per cent of those examined. This type of pattern, with similar enrichments relative to chondrites, has been reported in a 'Ca-rich inclusion' from Allende by GAST $\epsilon t$ al. (1970). Four of the inclusions exhibit patterns similar to that of $1 \mathrm{~A}$ and $14 \mathrm{~A}$, where the normalized Eu abundance is within error of that of $\mathrm{Sm}$.

The relative abundances of the rare earths expected in the condensates have purposely been ignored in previous discussions since existing thermodynamic data for the gaseous rare earth oxides are very poor and those for important crystalline species such as EuO are lacking entirely. The observed rare earth patterns can be rationalized, at least qualitatively, in the following manner. In the highly reducing environment of a high-temperature solar gas, solid solutions of the most easily reduced metals are the most stable. Since Eu displays a much more extensive chemical behavior in the +2 state than the other rare earths, it might be expected to concentrate in the very early condensates relative to them. Other inclusions, 


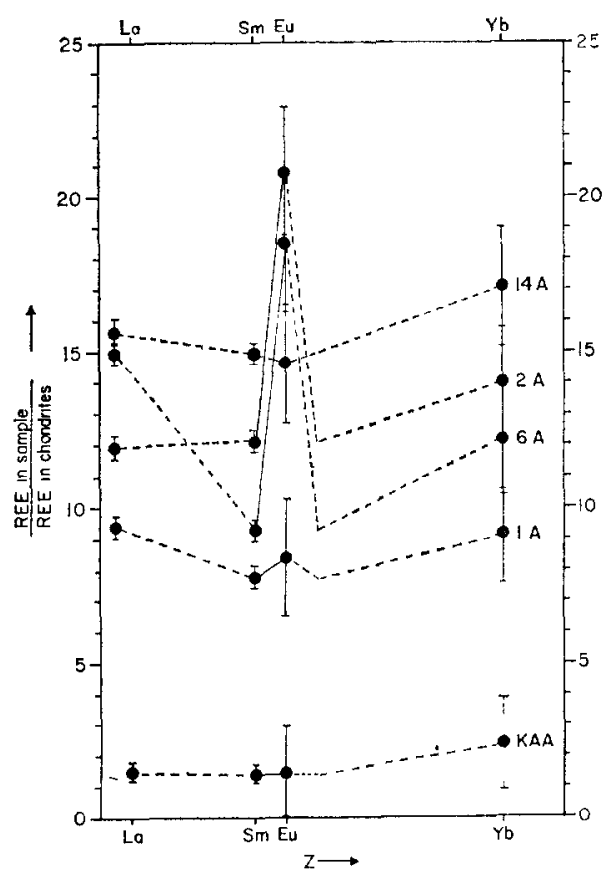

Fig. 4. Chondrite-normalized rare earth abundances for the $\mathrm{Ca}$-rich inclusions from Allende and the bulk meteorite. The inclusions are enriched in all the rare earths relative to the bulk meteorite. Some show Eu excesses, perhaps due to the condensation of $\mathrm{Eu}$ in the +2 state.

representing more advanced stages of condensation would show no preferential uptake of Eu since this element would have been joined by the other rare earths by this time. Kurat's (1970) description of the $\mathrm{Zr}-\mathrm{Y}$-rich perovskite in Lancé suggests that perovskite may also be the host for the rare earths.

It is interesting to note that terrestrial perovskites, many from highly differentiated igneous rocks, show a completely different rare earth pattern from that observed here (Borodin and BARINSkII, 1960). They are all enriched in the light rare earths relative to the heavy ones and show slight Eu depletions. This is a fairly general pattern observed among differentialed continental igneous rocks and is exhibited by these perovskites because they probably represent the dominant sink for the rare earths in their host rocks.

\section{Refractory element fractionations in chondrites}

In their study of chemical fractionations in meteorites, LARIMER and ANDERS (1970) pointed out that Ca, Al and 'Ti were depleted in ordinary and enstatite chondrites relative to carbonaceous chondrites and attributed this fractionation to loss of an early high-temperature condensate from a gas of solar composition. They also noted parallel depletion trends for $\mathrm{Hf}, \mathrm{La}, \mathrm{Sc}, \mathrm{Y}$ and $\mathrm{Zr}$. This study shows that the early Ca-Al-Ti-rich condensates should indeed be enriched in these elements also. Grossman (1972) showed that the mincralogical compositions, textural relations and major element abundances in the white achondritic inclusions in the C3's are those expected of the primitive condensates and of those phases whose removal from a gas of $\mathrm{Cl}$ composition is presumed to have caused the refractory 
element depletion of the ordinary and enstatite chondrites relative to the Cl's. The work of LARIMER and ANDERS (1970) shows that the depletion factors of most of the refractory elements are roughly constant in the ordinary chondrites $(0 \cdot 69)$ and in the enstatite chondrites $(0.50)$ relative to the carbonaceous chondrites, despite the fact that many of the analyses have come from different laboratories employing different analytical techniques on different meteorites and in spite of the notorious sample heterogeneity problem associated with meteorite analysis. This means that, if these fractionations were indeed produced by removal of high-temperature condensates from a gas having $\mathrm{Cl}$ composition for all but the most volatile elements, the fraction removed must contain the refractory elements in the same relative proportions as the starting material, with only minor fractionations relative to one another. The trace element data presented in Table 9 thus indicate that the inclusions in the C3's fulfil one more requirement of the removed material, since they are enriched in each of the refractory elements $\mathrm{La}, \mathrm{Sm}, \mathrm{Eu}, \mathrm{Yb}, \mathrm{Sc}$ and $\mathrm{Ir}$ relative to the Cl's by approximately the same factor, $18 \cdot 3$ to $25 \cdot 7$. If 100 per cent of each of these refractory elements and 100 per cent of the $\mathrm{Ca}, \mathrm{Al}, \mathrm{Ti}, \mathrm{Hf}, \mathrm{Y}, \mathrm{Zr}$ and $\mathrm{Th}$ were condensed into assemblages like the inclusions in the C3's, only $1 \cdot 3$ per cent and $2 \cdot 1$ per cent of the mass of the total condensable matter (23 and $38 \mathrm{wt} . \%$ of the high-temperature condensate) must be lost in the form of these aggregates during the accretion of the ordinary and enstatite chondrites, respectively, in order to account for the observed depletions.

\section{Conclustons}

The $\mathrm{Ca}-\mathrm{Al}$-rich inclusions in the Allende carbonaceous chondrite are enriched in $\mathrm{Sc}$, Ir and the rare earth elements by factors of $22 \cdot 8 \pm 2 \cdot 2$ relative to $\mathrm{Cl}$ chondrites. The chemical behavior of Ir is totally unlike that of Sc and the rare earths: in terrestrial igneous rocks, Ir is concentrated into the accessory chromite and sulphides of ultrabasic rocks while Sc enters the crystal structures of pyroxene and amphibole; in meteorites, Ir is usually siderophile and Sc is lithophile. Thermodynamic calculations show, however, that all these elements could have condensed from a cooling nebula of solar composition above or within the range of condensation temperatures of the major phases of the inclusions. Large enrichments of these refractory trace elements in the Ca-Al-rich inclusions thus provide further strong evidence that they are high-temperature condensates from the solar nebula. Differing degrees of fractionation of such crystalline materials from the vapor in different regions of the nebula could have generated the refractory element depletions of the ordinary and enstatite chondrites relative to the carbonaceous chondrites.

Acknowledgments-This work is based on the author's Ph.D. thesis. The interest, inspiration and advice of Dr. KArt K. Tungrian and Dr. Sydney P. Crark, Jr., my thesis supervisurs, are gratefully acknowledged.

My thanks go to Dr. E. A. KING, $J_{R}$. for providing me with precious specimens of the Allende inclusions and for permitting publication of these data before completion of other aspects of a co-operative study of these objects. I wish to thank Dr. J. B. ConLiss for the use of his factor analysis program and the Oregon State University Computer Center for machine time. Dr. D. P. KHARKar and Dr. A. Katz gave valuable advice regarding analytical techniques. I am indebted to J. Hasbrouck, T. EISEnSMith and M. ApPLequist for their technical assistance. 


\section{REFERENCES}

Ackermann R. J. and RaUt E. G. (1971) A high-temperature study of the stoichiometry, phase behavior, vaporization characteristics, and thermodynamic properties of the cerium + oxygen system. J. Chem. Therm. 3, 609-624.

Ackermann R. J., RaUh E. G. and Thone R. J. (1961) Thermodynamic properties of gaseous yttrium monoxide. Correlation of bonding in group III transition-metal monoxides. J.Chem. Phys. 40, 883-889.

Ames L. I., WALsh P. N. and White D. (1967) Rare earths. IV. Dissociation energies of the gaseous monoxides of the rare earths. J. Phys. Chem. "71, 2707-2718.

Anders E. (1971) How well do we know "cosmic" abundances? Geochim. Cosmochim. Acta 35, $516-522$.

Arrhenius G. (1972) Chemical effects in plasma condensation. In From Plasma to Planet, (editor A. Elvius), pp. 117-129. Almqvist \& Wiksell.

Arrhenius G. and Alfvén H. (1971) Fractionation and condensation in space. Earth Planet. Sci. Lett. 10, 253-267.

BamueCKei P. A. (1967) The distribution of gold and iridium in meteoritic and terrestrial materials. Ph.D. Thesis. University of Kientucky.

Baedecker P. A. (1972) Personal communication.

Bertine K. K., ChaN L. H. and Turekian K. K. (1970) Uranium determinations in deep-sea sediments and natural waters using fission tracks. Geochim. Cosmochim. Acta 34, 641648.

Borodin L. S. and Barinski R. L. (1960) Rare earths in perovskites (knopites) from massifs of ultrabasic alkalic rocks. Geochemistry 4, 343-351.

Brewer L. and Rosenblatt G. M. (1969) Dissociation energies and free energy functions of gaseous monoxides. In Advances in High Temperature Chemistry, (editor L. Eyring), Vol. II, pp. 1-83. Academic Press.

Cameron A. G. W. (1968) A new table of abundances of the elements in the solar system. In Origin and Distribution of the Elements, (editor L. H. Ahrens), pp. 125-143. Pergamon.

ChandrasekHaRaiah M. S. (1967) Volatilities of refractory inorganic compounds. In the Characterization of High-Temperature Vapors, (editor J. L. Margrave), pp. 495-507. Wiley.

Christophe M. (1968) Un chondre exceptionnel dans la météorite de Vigarano. Bull.Soc. Fr. Minéral. Cristallogr. 91, 212-214.

Christophe M. (1969) Etude minéralogique de la chondrite CIII de Lancé. In Meteorite Research, (editor P. M. Millman), pp. 492-499. Springer-Verlag.

Clatk S. P. Jr., Turekian K. K. and Grossman L. (1972) Model for the early history of tho earth. In The Nature of the Solid Earth, (editor E. C. Robertson), pp. 3-18. McGraw-Hill.

Clarke R. S. Jr., Jarosewich E., Mason B., Nelen J., Gomez M. and Hyde J. R. (1970) The Allende, Mexico, meteorite shower. Smithson. Contrib. Earth Sci. No. 5.

Совв J. C. (1967) A trace-element study of iron meteorites. J. Geophys. Res. 72, 1329-1341.

Crocket J. H. (1969) Platinum metals. In Handbook of Geochemistry, (editor K. H. Wedepohl), Vol. II.1. Springer-Verlag.

Crocket J. H., Keays R. R. and Hsien S. (1967) Precious metal abundances in some carbonaceous and enstatite chondrites. Aeochim. Cosmochim. Acta 31, 1615-1623.

Ehmann W. D., Baedecker P. A. and McKown D. M. (1970) Gold and iridium in meteorites and some selected rocks. Geochim. Cosmochim. Acta 34, 493-507.

EhmanN W. D. and Ginlum D. E. (1972) Platinum and gold in chondritic meteorites. Chem. Geol. 9, 1-11.

EhMann W. D. and Rebagay T. V. (1970) Zirconium and hafnium in meteorites by activation analysis. Aeochim. Cosmochim. Acta 34, 649-658.

Emery J. F., Strain J. E., O'Kelley G. D. and Lyon W. S. (1969) Nondestructive neutron activation analysis of tho Allondo metoorito. Radiochom. Radioarual. Lett. 1, 137141.

FlanaGan F. J. (1969) U.S. Geological Survey standards-II. First compilation of data for the now U.S.G.S. rocks. Geochim. Cosmochim. Acta 33, 81-120.

FLeischer M. (1969) U.S. Geological Survey Standards-I. Additional data on rocks G.I and W-1, 1965-1967. Geochim. Cosmochim. Acta 33, 65-79. 
Frondex C. (1970) Scandium. In Handbook of Geochemistry, (editor K. H. Wedepohl), Vol. II-2. Springer-Verlag.

Fuchs L. H. (1969) Oceurrence of cordierite and aluminous orthoenstatite in the Allende meteorite. Amer. Mineral. 54, 1645-1653.

Cast P. W., Hubbard N.J. and Wresmann H. (1970) Chemical composition and petrogenesis of basalts from Tranquillity Base. In Proc. Apollo 11 Lunar Sci.Conf., Geochim. Cosmochim. Acta Suppl. 1 1143-1163. Porgamon.

GrLld D. E. and Ehmann W. D. (1971) Noble metal determination in meteorites. Radiochim. Acte 16, 123-128.

Glassnez A. (1957) The thermochenical properties of the oxides, fluorides, and chlorides to $2500^{\circ} \mathrm{K}$. Argomne National Laboratory Rep. ANL-5750.

GremenLAND L. P. (1971) Variation of iridium in a differentiated tholeitic dolerite. Geochim. Cosmochim. Acta 35, 319-322.

Grossman L. (1972) Condensation in the primitive solar nebula. Geochim. Cosmochim. Acta 36, $597-619$.

Grossman L. and Cuark S. P. Jn. (1973) High-temperature condensates in chondrites and the environment in which they formed. Geochim. Cosmochim. Acta. 37, 635-649.

Hasim L. A., Haskin M. A., Frey F. A. and Wrideman T. R. (1968) Relative and absolute terrestrial abundances of the rare earths. In Origin and Distribution of the Elements, (editor L. H. Ahrens), pp. 889-912. Pergamon.

Honfey C. E. JR., Huber E.J. Jr. and BAKER F. B. (1968) The enthalpies, entropies, and Gibbs energies of formation of the rare earth oxides. In Progress in the Science and Technology of the Rare Earths, (editor L. Eyring), Vol. III, pp. 343-433. Pergamon.

Fultaren R., OrR R. L. and Kemley K. K. (1964 and later) Selected values of thermodynamic properties of metals and alloys. Supplements. University of California, Berkeley.

JANAF Thermochemical Tables (1966) First Addendum. Compiled by the Thermal Research Lab., Dow Chemical Company, Midland, Michigan.

JANAF Thermochemical Tables (1968) Third Addendum. Compiled by the Thermal Research Lab., Dow Chemical Company, Midland, Michigan.

Katz A. and Grossman L. (1973) Intercalibration of 17 standard silicates for 14 elements by instrumental neutron activation analysis. U.S. Geol. Surv. Prof. Pap. In press.

KEIL K., HUSs G. I. and WIIK H. B. (1969) The Leoville, Kansas meteorite: a polymict breceia of carbonaceous chondrites and achondrites. Abstract. In Meteorite Research, (editor P. M. Millman), p. 217. Reidel.

KELLEY K. K. (1960) Contributions to the data on theoretical metallurgy. XIII. High-temperature heat-content, heat-capacity, and entropy data for the elements and inorganic compounds. U.S. Bur. Mines Bull. 584.

Frearkar D. P. and Turekian K. K. (1971) Analyses of Apollo 11 and A pollo 12 rocks and soils by neutron activation. In Proc. Second Lunar Sci. Conf., Geochim. Cosmochim. Acta Suppl. 2, pp. 1301-1305. M.I.T. Press.

King E. A.Jr. (1969) Petrography and chemistry of the Pueblito de Allende meteorite. Abstract. EOS Trans. Amer. Geophys. Union 50, 459.

KING E. A. JR. et al. (1973) In preparation.

Kunat G. (1970) Zur Genese der Ca-Al-reichen Einschlüsse im Chondriten von Lancé. Earth Planet. Sci. Lett. 9, 225-231.

LARTMER J. W. and ANDERs E. (1970) Chemical fractionations in meteorites-III. Major element fractionations in chondrites. Geochim. Cosmochim. Acta 34, 367-387.

Lewis G. N., Randali M., Pitzer K. S. and Brewer L. (1961) Thermodynamics. Appendix 7. McGraw-Hill.

LORD H. C. III (1965) Molecular equilibria and condensation in a solar nebula and cool stellar atmospheres. Icarus 4, 279-288.

Marvin U. B., Wood J. A. and Dickey J. S. JR. (1970) Ca-Al rich phases in the Allende meteorite. Earth Planet. Sci. Lett. 7, 346-350.

Menninga C. (1971) Personal communication. 
Morgan J. W., Rebagay T. V., Showalter D. L., Nadkarny R. A., Gillum D. E., MoKown D. M. and EhManN W. D. (1969) Allende meteorite: some major and trace element abundances by neutron activation analysis. Nature 224, 789-791.

Müller O., Bafdecker P. A. and Wasson J. T. (1971) Relationship between siderophilicelement content and oxidation state of ordinary chondrites. Geochim. Cosmochim. Acta 35, 1121-1137.

Onuma N., Claytun R. N. and Mayeda T. K. (1972) Oxygen isotope cosmothermometer. Geochim. Cosmochim. Acta 36, 169-188.

Osborn T. W. (1971) Ph.D. Thesis. Oregon State University.

Osgons T. W., Smiti R. H. and Sommits R. A. (1973) Elemontal composition of individual chondrules from ordinary chondrites. Geochim. Cosmochim. Acta In press.

Perlman I. and Asaro F. (1969) Pottery analysis by neutron activation. Archaeometry 11, 2152.

Podosek F. and Lewis R. S. (1972) $\mathrm{I}^{129}$ and $\mathrm{Pu}^{244}$ abundances in white inclusions of the Allende meteorite. Earth Planet. Sci. Lett. 15, 101-109.

RaziN L. V., Khvostov V. P. and Novikov V. A. (1965) Platinum metals in the essential and accessory minerals of ultramafic rocks. Geochem. Int. 2, 118-131.

Robre R. A. and WaLdBaum D. R. (1968) Thermodynamic properties of minerals and related substances at $298 \cdot 15^{\circ} \mathrm{K}\left(25 \cdot 0^{\circ} \mathrm{C}\right)$ and one atmosphere $(1.013$ bars $)$ pressure and at higher temperatures. U.S. Geol. Surv. Bull. 1259.

Schmitt R. A., Smith R. H. and Olehy D. A. (1964) Rare-earth, yttrium and scandium abundances in meteoritic and terrestrial matter-II. Geochim. Cosmochim. Acta 28, 67-86.

TUREKIAN K. K. and Krarkar D. P. (1970) Neutron activation analysis of milligram quantities of Apollo 11 lunar rocks and soil. In Proc. Apollo 11 Lunar Sci. Conf., Geochim. Cosmochim. Acta Suppl. 1, pp. 1659-1664. Pergamon.

Wagman D. D., Evans W. H., Parker V. B., Halow I., Bailey S. M. and Schumm R. H. (1969) Selected values of chemical thermodynamic properties. NBS Technical Note 270-4.

Wagman D. D., Evans W. H., Parker V. B., Halow I., Bailey S. M., Schumm R. H. and ChURNex K. L. (1971) Selected values of chemical thermodynamic properties. NBS Technical Note 270-5.

Wakita H. and Schmitr R. A. (1970) Rare-earth and other elemental abundances in the Allende meteorite. Nature 22\%, 478-479.

Warren R. G. (1971) M.S. Thesis. Oregon State University.

WAsson J. T. (1969) The chemical classification of iron meteorites-III. Hexahedrites and other irons with germanium concentrations between 80 and 200 ppm. Geochim. Cosmochim. Acta $33,859-876$.

Wirk H. B. (1956) The chemical composition of some stony meteorites. Geochim. Cosmochim. Acta 9, 279-289. 